\title{
Cardiac Self-Efficacy and Fatigue One Year Post-Myocardial Infarction
}

\author{
Ulla Fredriksson-Larsson \\ Department of Health Sciences, University West, Trollhättan, Sweden \\ Email: ulla.fredriksson-larsson@hv.se
}

How to cite this paper: Fredriksson-Larsson, U. (2019) Cardiac Self-Efficacy and Fatigue One Year Post-Myocardial Infarction. Open Journal of Nursing, 9, 396-407. https://doi.org/10.4236/ojn.2019.94036

Received: March 6, 2019

Accepted: April 14, 2019

Published: April 17, 2019

Copyright () 2019 by author(s) and Scientific Research Publishing Inc. This work is licensed under the Creative Commons Attribution International License (CC BY 4.0).

http://creativecommons.org/licenses/by/4.0/

\begin{abstract}
Background: Patients and clinicians report that fatigue post-myocardial infraction (MI) is a bothersome symptom during recovery. Aim: The objective of this study was to explore whether there is a relationship between fatigue, cardiac self-efficacy, stress, breathlessness and physical activity one year post-MI. Method: Data were collected from a sample of patients diagnosed with MI one year earlier $(n=125)$ who responded to a questionnaire package measuring fatigue, cardiac self-efficacy, physical activity and the symptoms breathlessness and stress. Correlation and regression analyses were preformed to evaluate which factors were related to fatigue. Results: The results showed that cardiac self-efficacy was associated with fatigue $(r=-0.611, p=0.01)$ and the regression model, controlling for breathlessness and stress, showed an explained variance of $72 \%$ one year post-MI. Physical activity was not significant in this model and did not predict fatigue during this time period. Conclusion: Post-MI fatigue-relief support should rely not only on identification of fatigue and other concurrent symptoms, but also on identification of cardiac self-efficacy.
\end{abstract}

\section{Keywords}

Cardiac Self-Efficacy, Fatigue, Myocardial Infarction, Regression Analyses

\section{Introduction}

Prevention measures and acute medical treatment of myocardial infarction (MI) have contributed to a decreased event rate and to improved survival 30 days post-MI [1], indicating that today more patients return to work, are able to be active and participate in society post-MI than was previously the case. Research has shown that, during the post-MI recovery period, persons experienced illness-related symptoms such as breathlessness and pain [2], stress [3] and fatigue 
[4]. High stress post-MI was associated with fear of dying in connection with discharge [5] [6], but there is a lack of research on how stress influences fatigue post-MI [7]. However, studies have shown that fatigue has been conceptualized as a warning sign indicating an accumulation of stress [8] as well as that fatigue plays a mediating role between stress and perceived poor health. Stress appraisal seems to be based on personal values, beliefs and goals, and the options for coping are determined by the person's health and biopsychosocial resources [9]. The symptom of breathlessness post-MI appears to predict fatigue two months post-MI, and both indications are associated with less physical activity six months post-MI [10]. It can be difficult to distinguish clinical symptoms of heart failure or other pathological conditions from simple physical decline in middle-age and among older persons [11]. However, a Cochrane review showed important benefits of exercise-based cardiac rehabilitation in people with cardiac heart disease (CHD) in the form of improvements in health-related quality of life, compared to people with CHD who did not exercise [12].

Fatigue is a common symptom among almost half of people treated for MI [2] and predicts lower health-related quality of life during the recovery period after the cardiac event [13]. The consequences of fatigue in daily life include a sense of reduced ability to manage daily life activities [14]. Two years after the heart attack, the degree of fatigue with or without coexisting possible/probable depression has been shown to remain higher in comparison with the general population [15]. The symptom of fatigue during post-MI recovery seemed to be predicted by experiences of stress and breathlessness and could be reduced by use of coping strategies characterized by "changes in values" [16].

The most recent guidelines for cardiovascular rehabilitation underline the importance of focusing on more than just physical health during the rehabilitation process, because rehabilitation is not sufficiently effective if patients' psychosocial condition is not adequality considered [17]. Use of a combination of psychological and physical interventions, rather than only focusing on pathology prevention, provides a systematic approach to generating a more comprehensive and potentially more useful etiological summary. Experiencing symptoms, for example fatigue, often has meaning beyond the diagnosis and provides a basis for expressing vulnerability and fears [18]. By measuring subjective experience of symptoms, the analyst can offer insights into the personal meaning of illness as well as information about bodily and social restrictions [19].

Among the (psychological) factors that play a protective role post-MI, self-efficacy is an important factor that has been shown to predict a wide range of effective health-promoting behaviors in the context of illness [20] [21] [22]. Self-efficacy theory states that psychological processes, whatever their form, alter the level and strength of self-efficacy. Expectations of a person's self-efficacy determine whether coping behavior will be exhibited and how long it will be sustained in the face of obstacles and aversive experience. Self-efficacy beliefs are said to influence not only the courses of action pursued, but also the effort ex- 
pended and endurance shown when facing difficulties. In the context of illness management, self-efficacy beliefs refer to a person's confidence in his/her ability to successfully execute health-related behaviors [23]. Comparable to general and specific perceived competence, self-efficacy can be disease- or behavior-specific [24]. Self-efficacy is a vital factor in both initiating and maintaining health behaviors in persons with coronary artery diseases. Studies have indicated that factors related to a subject's perception of the disease are more likely to be associated with cardiac self-efficacy than with disease knowledge. These findings could be used in clinical practice to consider persons' perceptions of their coronary heart disease and awareness of risk factors as well as to encourage cardiac self-efficacy so as to promote health behaviors [25]. Low cardiac self-efficacy was found to predict increased risk for heart failure and hospitalization in persons with stabile coronary heart disease [26]. Also, persons with poor self-efficacy regarding physical activity have a significantly higher incidence of cardiovascular events [21]. The Cardiac Self-efficacy scale (CSE scale), developed by [27], has been used to measure specific self-efficacy regarding both symptom interpretation and function and refers to persons' ability to manage illness-specific outcomes.

There is still no evidence concerning how post-MI fatigue can be prevented or treated. It is possible that cardiac self-efficacy could be a fruitful approach to investigating persons' self-efficacy beliefs regarding dealing with recovery post-MI and, thereby, to preventing or treating fatigue. Therefore, the present study aim is to explore whether there is a relationship between fatigue, self-efficacy, stress, breathlessness and physical activity one year post-MI.

\section{Method}

\subsection{Design}

This was a cross-sectional questionnaire survey with a descriptive design aimed at investigating what factors are associated with fatigue one year post-MI. Mapping factors associated with fatigue over time may allow us to find relationships when there is no significant difference in fatigue between two months and one year post-MI.

\subsection{Population}

The present one-year follow-up study consisted of 125 of the 164 persons who met the diagnostic criteria for MI between March 2011 and March 2012 (in a coronary care unit in western Sweden) and who completed the questionnaire items measuring fatigue, self-efficacy, stress, breathlessness and physical activity one year post-MI (response rate 75\%). Eligible for inclusion were persons $\leq 75$ years with confirmed MI based on electrocardiographic, symptom and enzymatic criteria.

The sample consisted of 28 women and 97 men who could speak and understand Swedish as well as read and comprehend the study instructions. 


\subsection{Instrument}

The Swedish version of the CSE scale [27] (Sullivan et al., 1998) has been validated and is used as a tool, combined with in-depth dialog, to promote person-centered care in clinical practice [28] (Fors, Ulin, Cliffordson, Ekman, \& Brink, 2014). It consists of 12 items, and responses are made on a 5-point Likert scale $(0=$ not at all, $1=$ somewhat confident, $2=$ moderately confident, $3=$ very confident, $4=$ completely confident). The questionnaire was confirmed with one global dimension and is equally suitable as a three-factor model including the subscales: control symptoms, control illness and maintaining function.

The Somatic Health Complaints Questionnaire (SHCQ) [29] measures somatic health problems and investigates four dimensions: pain, breathlessness, fatigue and unrest (How have you felt the past week?). It consists of 13 items rated on a 6-point scale ranging from "never" to "always" during the past week. For the pain dimension, the possible range was $4-24$, for the breathlessness dimension the range was $2-12$, and for the unrest dimension the range was $3-18$. Higher scores indicate more severe somatic health problems. In the present study, the fatigue dimension was excluded from the analysis due to the use of another fatigue inventory.

The Post-Myocardial Infraction Fatigue (PMIF) scale [30] is a new Swedish questionnaire validated to measure post-MI fatigue in three dimensions: physical, mental and cognitive fatigue. It is also suitable for summing the items to obtain a total score representing a global post-MI fatigue dimension. The PMIF is validated based on empirical data gathered in coronary heart disease contexts, ending in a psychometric evaluation. The PMIF consists of 15 items rated on a 5-pointscale ranging from "not at all" to "all the time". (How often have you experienced $X$ during the past week?)

Stress was measured using a single-item measurement of stress symptoms [31]. This item converges with items on psychological symptoms, well-being and sleep disturbance and covers the general experience of stress. ("Stress refers to a situation in which a person feels tense, restless, nervous or anxious or is unable to sleep at night because his/ her mind is constantly troubled. Do you currently feel this kind of stress?") A 5-point rating scale ranging from "not at all" to "very much", with a possible total score range of $1-5$. Higher scores indicate greater stress. The convergent validity of the single-item measure of stress symptoms was confirmed; the measure was useful in assessing associations between stress and fatigue and could therefore indicate post-MI fatigue experiences [32].

Self-reported physical activity level was rated on the modernized 4-level Saltin-Grimby Physical Activity Level Scale (SGPALS), which was originally developed by Saltin and Grimby [33]. A single question is used: "How much do you exert physically activity during last three months?" Four response options were given, making up the four self-reported physical activity groups: physically inactive, some light physical activity, regular physical activity and training and regular hard physical training for competition sports. This scale differentiates be- 
tween participants who are primarily sedentary (level 1), engage in light physical activity (e.g., walking, ordinary gardening, bicycling to work and dancing) for at least two hours a week (level 2), report at least two hours a week of moderate physical activity (e.g. aerobics, tennis, dancing, swimming, playing soccer, heavy gardening; level 3), or engage for at least five hours a week in vigorous activity on several occasions (level 4). The scale has shown good validity and reliability [34].

\subsection{Data Collection Procedure}

The respondents were consecutively recruited by three research nurses during the first week in a coronary care unit in western Sweden from March 2011-March 2012. The respondents had been treated for MI and were asked to participate in a longitudinal study of health post-MI conducted two months, one year and two years after MI by the first author as well as to complete the follow-up questionnaires. The inclusion criteria were $\leq 75$ years of age and meeting the diagnostic criteria for MI. The exclusion criteria were communicative disabilities, cognitive disorientations and other severe diseases [16].

\subsection{Statistics}

SPSS statistical software version 21 was used. Imputation was used to replace missing variables with the average value for the item. Six variables were missing across all questionnaires. Descriptive statistics are presented as means and standard deviations (SD), and analytic statistics comprise correlation analyses. Both parametric and nonparametric (Spearman) correlations were calculated, however, no major discrepancies were found. To identify predictors of fatigue and to what extent they predict fatigue one year post-MI, a regression analysis was performed.

\subsection{Ethical Considerations}

The Regional Ethical Review Board in Gothenburg (720-10) approved the study. The participants were informed about the study aim and procedures both in writing and verbally and were given adequate time to consider participation during the first week in hospital. Data collection was performed by trained research nurses. Informed written consent was obtained from those who wished to participate.

\section{Results}

\subsection{Background Characteristics}

One year after myocardial infarction, 125 persons of the 165 persons from baseline completed the questionnaire package. The majority were men (77\%), and the mean age was $63.8 \pm 7$, range $44-75$. Thirty-nine percent were employed and 83 percent were cohabiting one year post-MI. Demographics and clinical data are presented in (Table 1). 
Table 1. Clinical characteristics of the study population $(\mathrm{N}=125)$.

\begin{tabular}{ccc}
\hline & & Range \\
\hline Age, mean (SD) and range & $63.8(7.0)$ & $44-75$ \\
Women, n (\%) & $28(23)$ & \\
Intervention, n (\%) & $82(65)$ & \\
Percutaneous Coronary Intervention, n (\%) & $5(4)$ & \\
Coronary Artery Bypass Graft, n (\%) & $7(6)$ & \\
Smoking, n (\%) & $103(83)$ \\
Cohabit, n (\%) & $49(39)$ & \\
Occupationally employed, n (\%) & \\
Physical activity, n (\%) & $23(19)$ \\
Mostly sitting still & $66(54)$ & \\
Light physical activity & $28(22)$ & \\
More grueling activity & $5(4)$ & \\
Intense regular exercise
\end{tabular}

\subsection{Descriptive Statistic}

The mean of Post-Myocardial Infraction Fatigue (PMIF) scale was $15.99 \pm 12.42$ and Cardiac Self-efficacy $34.39 \pm 7.53$. Descriptive statistics for variables included in the univariate analysis are presented in (Table 2).

\subsection{Univariate Analysis}

The univariate analyses identified associations between fatigue and the independent variables stress $(\mathrm{p}=0.790)$, breathlessness $(\mathrm{p}=0.509)$, physical activity $(\mathrm{p}=$ $-0.319)$ and self-efficacy $(\mathrm{p}=-0.611)$. The $\mathrm{p}$-values from the univariate analysis for fatigue are listed in (Table 3 ).

\subsection{Multiple Regression Analysis}

The multivariate regression analyses aimed at identifying how much of the variance in fatigue could be explained by the regression model, which included cardiac self-efficacy $\left(r^{2}=0.373\right)$, symptoms of breathlessness $\left(r^{2}=0.259\right)$ and stress $\left(r^{2}=0.623\right)$. The regression model summary explained 72.4 percent of the variance in fatigue.

The stress variable made the greatest unique contribution (Standardize beta coefficients $=0.593$ ), although cardiac self-efficacy (Standardize beta coefficients $=-0.218$ ) and breathlessness (Standardized beta coefficients $=0.204$ ) also made a statistically significant contribution to explaining the variance in fatigue. The R-square and Standardized beta coefficients are presented in (Table 4).

Stress had the greatest influence; each unit increase in stress increases fatigue by 0.79 units, while each unit of cardiac self-efficacy decreases fatigue by -0.61 units. Also, breathlessness was identified as being associated with and increasing fatigue by 0.51 units. 
Table 2. Descriptive statistics on variables.

\begin{tabular}{cccccc}
\hline $\begin{array}{c}\text { Post-Myocardial Infarction } \\
\text { Fatigue Scale (PMIF) }\end{array}$ & $15.99 \pm 12.42$ & 13 & 125 & 0 to 45 & $0-45$ \\
Cardiac Self-Efficacy & $34.39 \pm 7.53$ & 35.5 & 124 & 14 to 48 & $0-48$ \\
Breathlessness & $4.90 \pm 2.39$ & 4 & 125 & 2 to 11 & $2-12$ \\
Stress & $2.09 \pm 1.08$ & 2 & 125 & 1 to 5 & $1-5$ \\
Physical Activity & $2.13 \pm 0.75$ & 2 & 121 & 1 to 4 & $1-4$ \\
\hline
\end{tabular}

Table 3. Correlations between post-myocardial infarction fatigue scale, cardiac self-efficacy, breathlessness, stress and physical activity.

\begin{tabular}{lccccc}
\hline Scale & 1 & 2 & 3 & 4 & 5 \\
\hline 1) PMIF & 1 & $-0.611^{* *}$ & $0.509^{* *}$ & $0.790^{* *}$ & $-0.319^{* *}$ \\
2) Cardiac self-efficacy & & 1 & $-0.328^{* *}$ & $-0.506^{* *}$ & $0.402^{* *}$ \\
3) Breathlessness & & & 1 & $0.363^{* *}$ & $-0.275^{* *}$ \\
4) Stress & & & & 1 & $-0.188^{*}$ \\
5) Physical activity & & & & & 1 \\
\hline
\end{tabular}

${ }^{* *}$ Correlation is significant at the 0.01 level (2-tailed); ${ }^{\star}$ Correlation is significant at the 0.05 level (2-tailed).

Table 4. Regression analysis. Explaining $72.4 \%$ of the variance on fatigue one year post-MI.

\begin{tabular}{cccc}
\hline & $\mathrm{R}^{2}$ & $\begin{array}{c}\text { Standardized } \\
\text { Coefficients Beta }\end{array}$ & Sig. \\
\hline Cardiac self-efficacy & 0.373 & -0.218 & 0.01 \\
Breathlessness & 0.259 & 0.204 & 0.00 \\
Stress & 0.623 & 0.593 & 0.00 \\
Physical activity & 0.102 & -0.064 & 0.240 \\
$\begin{array}{c}\text { The final correlation included CSE } \\
\text { breathlessness and stress }\end{array}$ & 0.724 & 0.269 & 0.00 \\
\hline
\end{tabular}

\section{Discussion}

The study showed a clear association between fatigue and stress, cardiac self-efficacy, physical activity and breathlessness one year post-MI. Physical activity and cardiac self-efficacy showed a negative correlation with fatigue, which means higher levels of self-efficacy and physical activity could decrease fatigue one year post-MI.

Physical activity is important in secondary coronary heart disease (CHD) prevention [35]. It is also important when persons, post-MI, experience anxiety and fear another MI again [36]. Fatigue significantly influenced physical activity post-MI [37], and $22 \%$ - $40 \%$ persons do not meet the physical activity recommendations for cardiovascular benefits [38]. Our results did not find physical activity to associate with fatigue one year post-MI, Physical activity is a measure on its own, but due to the combination of other factors its effect disappears in the regression analysis. However, physical activity is an "easy measure to per- 
form", and our results show that it is associated with decreased fatigue, breathlessness and stress as well as increased self-efficacy.

According to European guidelines, health and medical care professionals need to consider whether there is sufficient focus on patients' psychosocial condition during the rehabilitation process [17], though there are no recommendations in the guidelines for measures to prevent post-MI fatigue. It is important to implement psychological interventions in rehabilitation therapy, the aim of such interventions being to improve patients' quality of life by managing their illness representations and strengthening their sense of personal control in adhering to intervention activities. Studies have indicated that factors related to a subject's perception are more likely to be associated with self-efficacy than with disease knowledge [25] which underscores the importance of considering illness representations and cardiac self-efficacy beliefs in efforts to improve well-being among cardiovascular disease patients [39]. The present study indicates that cardiac self-efficacy is the only variable that predicted fatigue (in a negative correlation) and is an important factor for fatigue relief post-MI. Also in the present study, cardiac self-efficacy shows associations in the univariate analysis with decreased stress and breathlessness, both of which are significant as regards developing fatigue symptoms post-MI.

The study showed an association between stress and fatigue two months post-MI, but also a significant difference in fatigue level between persons who experienced high stress and persons with low stress [32]. Our regression analysis one year post-MI revealed that stress and breathlessness were associated with fatigue. The univariate analyses showed that stress and symptoms of breathlessness decreased when cardiac self-efficacy was high. Also, physical activity level decreased with higher levels of stress. Earlier studies have shown that improvements in cardiac self-efficacy one year after cardiovascular disease enable better self-management of cardiovascular lifestyle with regard to physical activity and food choice [40] and that self-efficacy can be changed through nursing interventions [41]. Early intervention, continuous monitoring and support of persons' ability to manage their symptoms are important in promoting their confidence in long-term management of long-term management of lifestyle changes [42] and significant improvements in behavioral outcomes [43], which could be important steps in a fatigue-relief strategy.

\section{Conclusion}

In cardiac rehabilitation programs today there are typically few or no recommendations at all concerning strategies for dealing with fatigue post-MI. The present findings indicated that post-MI fatigue-relief support may rely not only on identification of fatigue and other concurrent symptoms, but also on identification of cardiac self-efficacy.

\section{Limitations}

In the present study, the inclusion criteria were having received a diagnosis of 
myocardial infarction and being younger than 75 years of age. Today the proportion of older people is increasing and thus, persons older than 75 years must be tested further. Moreover, the present study was cross-sectional, which could be seen as a limitation. Despite these limitations, the present results contribute to our understanding of self-efficacy and its association with post-MI fatigue.

\section{Conflicts of Interest}

The author declares no conflicts of interest regarding the publication of this paper.

\section{References}

[1] Smolina, K., Wright, F.L., Rayner, M. and Goldacre, M.J. (2012) Determinants of the Decline in Mortality from Acute Myocardial Infarction in England between 2002 and 2010: Linked National Database Study. BMJ, 344, d8059. https://doi.org/10.1136/bmj.d8059

[2] Alsén, P., Brink, E., Brändström, Y., Karlson, B.W. and Persson, L.O. (2010) Fatigue after Myocardial Infarction: Relationships with Indices of Emotional Distress, and Sociodemographic and Clinical Variables. International Journal of Nursing Practice, 16, 326-334. https://doi.org/10.1111/j.1440-172X.2010.01848.x

[3] Shemesh, E., Yehuda, R., Milo, O., Dinur, I., Rudnick, A., Vered, Z. and Cotter, G. (2004) Posttraumatic Stress, Nonadherence, and Adverse Outcome in Survivors of a Myocardial Infarction. Psychosomatic Medicine, 66, 521-526. https://doi.org/10.1097/01.psy.0000126199.05189.86

[4] Brink, E., Karlson, B. and Hallberg, L.R.M. (2002) Health Experiences of First-Time Myocardial Infarction: Factors Influencing Women's and Men's Health-Related Quality of Life after Five Months. Psychology, Health and Medicine, 7, 5-16. https://doi.org/10.1080/13548500120101522

[5] Arnold, S.V., Smolderen, K.G., Buchanan, D.M., Li, Y. and Spertus, J.A. (2012) Perceived Stress in Myocardial Infarction: Long-Term Mortality and Health Status Outcomes. JACC, 60, 1756-1763. https://doi.org/10.1016/j.jacc.2012.06.044

[6] Ginzburg, K., Kutz, I., Koifman, B., Roth, A., Kriwisky, M., David, D. and Bleich, A. (2016) Acute Stress Disorder Symptoms Predict All-Cause Mortality among Myocardial Infarction Patients: A 15-Year Longitudinal Study. Annals of Behavioral Medicine, 50, 177-186. https://doi.org/10.1007/s12160-015-9744-x

[7] Kocalevent, R.D., Hinz, A., Brähler, E. and Klapp, B.F. (2011) Determinants of Fatigue and Stress. BMC Research Notes, 4, 238.

https://doi.org/10.1186/1756-0500-4-238

[8] Watanabe, Y. (2008) Preface and Mini-Review: Fatigue Science for Human Health. In: Fatigue Science for Human Health, Springer, Tokyo, 5-11.

[9] Lazarus, R.S. and Folkman, S. (1984) Stress, Appraisal, and Coping. Springer Publishing Company, Berlin.

[10] Brändström, Y., Brink, B., Grankvist, G., Alsén, P., Herlitz, J. and Karlsson, B.W. (2009) Physical Activity Six Months after a Myocardial Infarction. International Journal of Nursing Practice, 15, 191-197.

https://doi.org/10.1111/j.1440-172X.2009.01744.x

[11] Azevedo, A., Bettencourt, P., Pimenta, J., Friões, F., Abreu-Lima, C., Hense, H. and Barros, H. (2007) Clinical Syndrome Suggestive of Heart Failure Is Frequently At- 
tributable to Non-Cardiac Disorders-Population-Based Study. European Journal of Heart Failure, 9, 391-396. https://doi.org/10.1016/j.ejheart.2006.10.017

[12] Anderson, L., Thompson, D.R., Oldridge, N., Zwisler, A., Rees, K., Martin, N. and Taylor, R.S. (2016) Exercise-Based Cardiac Rehabilitation for Coronary Heart Disease. Cochrane Database of Systematic Reviews, No. 1, CD001800. https://doi.org/10.1002/14651858.CD001800.pub3

[13] Brink, E., Grankvist, G., Karlson, B.W. and Hallberg, L.R.-M. (2005) Health-Related Quality of Life in Women and Men One Year after Acute Myocardial Infarction. Quality of Life Research, 14, 749-757. https://doi.org/10.1007/s11136-004-0785-Z

[14] Fredriksson-Larsson, U., Alsén, P. and Brink, E. (2013) I've Lost the Person I Used to Be Experiences of the Consequences of Fatigue Following Myocardial Infarction. International Journal of Qualitative Studies on Health and Well-Being, 8, Article ID: 20836. https://doi.org/10.3402/qhw.v8i0.20836

[15] Alsén, P. and Brink, E. (2013) Fatigue after Myocardial Infarction-A Two-Year Follow-Up Study. Journal of Community Nursing, 22, 11-12.

https://doi.org/10.1111/jocn.12114

[16] Fredriksson-Larsson, U., Alsén, P., Karlson, B.W. and Brink, E. (2015) Fatigue Two Months after Myocardial Infarction and Its Relationships with Other Concurrent Symptoms, Sleep Quality and Coping Strategies. Journal of Community Nursing, 24, 2192-2200.

[17] Perk, J., De Backer, G., Gohlke, H., Graham, I., Reiner, Ž., Verschuren, M. and Cifkova, R. (2012) European Guidelines on Cardiovascular Disease Prevention in Clinical Practice (Version 2012): The Fifth Joint Task Force of the European Society of Cardiology and Other Societies on Cardiovascular Disease Prevention in Clinical Practice (Constituted by Representatives of Nine Societies and by Invited Experts) Developed with the Special Contribution of the European Association for Cardiovascular Prevention \& Rehabilitation (EACPR). European Heart Journal, 33, 1635-1701. https://doi.org/10.1093/eurheartj/ehs092

[18] Kleinman, A. (1988) The Illness Narratives: Suffering, Healing, and the Human Condition. Basic Books.

[19] Ekman, I., et al. (2011) Person-Centered Care-Ready for Prime Time. European Journal of Clinical Nutrition, 10, 248-251.

[20] Bandura, A. (2004) Health Promotion by Social Cognitive Means. Horticulture, Environment, and Biotechnology, 31, 143-164.

https://doi.org/10.1177/1090198104263660

[21] Bergström, G., Börjesson, M. and Schmidt, C. (2005) Self-Efficacy Regarding Physical Activity Is Superior to Self-Assessed Activity Level, in Long-Term Prediction of Cardiovascular Events in Middle-Aged Men. BMC Public Health, 15, 1.

[22] Luszczynska, A. and Sutton, S. (2006) Physical Activity after Cardiac Rehabilitation: Evidence That Different Types of Self-Efficacy Are Important in Maintainers and Relapsers. Rehabilitation Psychology, 51, 314. https://doi.org/10.1037/0090-5550.51.4.314

[23] Bandura, A. (1977) Self-Efficacy: Toward a Unifying Theory of Behavioral Change. Psychological Review, 84, 191. https://doi.org/10.1037/0033-295X.84.2.191

[24] Bandura, A. (1997) Self-Efficacy: The Exercise of Control. Freeman, New York.

[25] Kang, Y. and Yang, I.S. (2013) Cardiac Self-Efficacy and Its Predictors in Patients with Coronary Artery Diseases. Journal of Clinical Neurology, 22, 2465-2473.

https://doi.org/10.1111/jocn.12142 
[26] Sarkar, U., Ali, S. and Whooley, M.A. (2007) Self-Efficacy and Health Status in Patients with Coronary Heart Disease: Findings from the Heart and Soul Study. Psychosomatic Medicine, 69, 306. https://doi.org/10.1097/PSY.0b013e3180514d57

[27] Sullivan, M.D., LaCroix, A.Z., Russo, J. and Katon, W.J. (1998) Self-Efficacy and Self-Reported Functional Status in Coronary Heart Disease: A Six-Month Prospective Study. Psychosomatic Medicine, 60, 473-478. https://doi.org/10.1097/00006842-199807000-00014

[28] Fors, A., Ulin, K., Cliffordson, C., Ekman, I. and Brink, E. (2015) The Cardiac Self-Efficacy Scale, a Useful Tool with Potential to Evaluate Person-Centred Care. European Journal of Cardiovascular Nursing, 14, 536-543. https://doi.org/10.1177/1474515114548622

[29] Brink, E., Cliffordson, C., Herlitz, J. and Karlson, B.W. (2007) Dimensions of the Somatic Health Complaints Questionnaire (SHCQ) in a Sample of Myocardial Infarction Patients. European Journal of Cardiovascular Nursing, 6, 27-31. https://doi.org/10.1016/j.ejcnurse.2006.03.003

[30] Brink, E., Fredriksson-Larsson, U., Alsén, P., Lång, M. and Cliffordson, C. (2018) Development of a Tool for Assessment of Post-Myocardial Infarction Fatigue. Open Journal of Nursing, 8, 811-822. https://doi.org/10.4236/ojn.2018.811061

[31] Elo, A.-L., Leppänen, A. and Jahkola, A. (2003) Validity of a Single-Item Measure of Stress Symptoms. Scandinavian Journal of Work, Environment \& Health, 29, 444-451. https://doi.org/10.5271/sjweh.752 https://www.jstor.org/stable/40967322

[32] Fredriksson-Larsson, U., Brink, E., Grankvist, G., Jonsdottir, I.H. and Alsén, P. (2015) The Single-Item Measure of Stress Symptoms after Myocardial Infarction and Its Association with Fatigue. Open Journal of Nursing, 5, 345. https://doi.org/10.4236/ojn.2015.54037

[33] Saltin, B. and Grimby, G. (1968) Physiological Analysis of Middle-Aged and Old Former Athletes. Circulation, 8, 1104-1115. https://doi.org/10.1161/01.CIR.38.6.1104

[34] Aires, N., Selmer, R. and Thelle, D. (2003) The Validity of Self-Reported Leisure Time Physical Activity, and Its Relationship to Serum Cholesterol, Blood Pressure and Body Mass Index. A Population Based Study of 332,182 Men and Women Aged 40-42 Years. European Journal of Epidemiology, 18, 479-485.

https://doi.org/10.1023/A:1024682523710

[35] Booth, J., Levitan, E.B., Brown, T., Farkouh, M., Safford, M. and Munther, P. (2014) Effect of Sustaining Lifestyle Modifications (Nonsmoking, Weight Reduction, Physical Activity, and Mediterranean Diet) after Healing of Myocardial Infarction, Percutaneous Intervention, or Coronary Bypass (from the Reasons for Geographic and Racial Differences in Stroke Study). The Atlanta Journal-Constitution, 113, 1933-1940. https://doi.org/10.1016/j.amjcard.2014.03.033

[36] Junehag, L., Asplund, K. and Svedlund, M. (2014) A Qualitative Study: Perceptions of the Psychosocial Consequences and Access to Support after an Acute Myocardial Infarction. Intensive \& Critical Care Nursing. The Official Journal of the BACCN, 30, 22-30. https://doi.org/10.1016/j.iccn.2013.07.002

[37] Crane, P.B., Abel, W.M. and McCoy, T.P. (2015) Fatigue and Physical Activity after Myocardial Infarction. Barisan Revolusi Nasional, 17, 276-284.

[38] Zhao, G., Ford, E.S., Li, C. and Mokdad, A.H. (2008) Are United States Adults with Coronary Heart Disease Meeting Physical Activity Recommendations? The American Journal of Cardiology, 101, 557-561. 
https://doi.org/10.1016/j.amjcard.2007.10.015

[39] Greco, A., Steca, P., Pozzi, R., Monzani, D., Malfatto, G. and Parati, G. (2015) The Influence of Illness Severity on Health Satisfaction in Patients with Cardiovascular Disease: The Mediating Role of Illness Perception and Self-Efficacy Beliefs. Behavioral Medicin, 41, 9-17. https://doi.org/10.1080/08964289.2013.855159

[40] Sol, B.G., van der Graaf, Y., van Petersen, R. and Visseren, F.L. (2011) The Effect of Self-Efficacy on Cardiovascular Lifestyle. European Journal of Clinical Nutrition, 10, 180-186. https://doi.org/10.1016/j.ejcnurse.2010.06.005

[41] Sol, B.G., van der Graaf, Y., van der Bijl, J.J., Goessens, B.M. and Visseren, F.L. (2008) The Role of Self-Efficacy in Vascular Risk Factor Management: A Randomized Controlled Trial. Patient Education and Counseling, 71, 191-197. https://doi.org/10.1016/j.pec.2007.12.005

[42] Lau-Walker, M. (2007) Importance of Illness Beliefs and Self-Efficacy for Patients with Coronary Heart Disease. Job Accommodation Network, 60, 187-198. https://doi.org/10.1111/j.1365-2648.2007.04398.x

[43] Kashani, M., Eliasson, A.H., Walizer, E.M., Fuller, C.E., Engler, R.J., Villines, T.C. and Vernalis, M.N. (2016) Early Empowerment Strategies Boost Self-Efficacy to Improve Cardiovascular Health Behaviors. Global Journal of Health Science, 8, 322-330. https://doi.org/10.5539/gihs.v8n9p322 